\title{
PENGARUH PERMAINAN HALANG RINTANG TERHADAP KEMAMPUAN ORIENTASI DAN MOBILITAS \\ PADA SISWA TUNANETRA DI SLB-A TPA JEMBER TAHUN AJARAN 2018/2019
}

\author{
Muh. As’ad Nuril Arifin \\ SLB-A TPA Jember
}

E-mail: asadnurilarifin@gmail.com

\begin{abstract}
Abstrak
Penelitian ini bertujuan untuk mengetahui pengaruh permainan halang rintang terhadap kemampuan orientasi dan mobilitas pada siswa Tunanetra di SLB-A TPA Jember Tahun ajaran Penelitian ini menggunakan metode Kuantitatif. Metode analisa menggunakan Uji Sign Test. Jenis penelitian yang digunakan adalah Pre-experiment pada Statistik non parametrik dengan desain penelitian one-group pre test - post test design. Subyek dalam penelitian ini adalah 5 siswa tunanetra dengan nilai rata-rata sebelum treatment (pre-test) yaitu 59 dan nilai rata-rata sesudah treatment (posttest) yaitu 77. Dari hasil uji menggunakan $\alpha=5 \%(1,645)$ pada uji sign test diperoleh nilai Zh $=2,236>$ Ztabel $=1,645$. Hasil penelitian menunjukkan bahwa H0 ditolak dan Ha diterima. Dari hasil tersebut terbukti bahwa permainan halang rintang berpengaruh terhadap kemampuan orientasi mobilitas siswa tunanetra.
\end{abstract}

Kata kunci : Permainan halang rintang, Orientasi dan Mobilitas, Tunanetra.

\section{PENDAHULUAN}

Menurut Schulz (dalam Hadi, 2005, hal. 36) kerusakan penglihatan adalah istilah umum yang digunakan untuk menggambarkan semua bentuk kehilangan penglihatan, buta digunakan untuk mendiskripsikan siswa yang betulbetul mengutamakan metode perabaan dalam belajarnya.

Kondisi ini disebabkan oleh kerusakan pada mata, syaraf optic dan atau bagian otak yang mengolah stimulus visual. Oleh karena itu siswa tunanetra adalah siswa yang mengalami kondisi kerusakan pada indera penglihatannya. Akibatnya kerusakan pada indera mata tersebut berdampak pada kekurangan penglihatannya atau sama sekali tidak dapat melihat terhadap obyek-obyek benda yang ada di sekitar. Sehinggaamuncul berbagai kendala di kehidupan siswa tunanetra yang harus segera diatasi. Selain itu, dalam pendidikan formal siswa tunanetra perlu mempelajari orientasi dan mobilitas guna dapat berinteraksi di lingkungan sekitar secara mandiri.

Orientasi dan mobilitas merupakan dua keterampilan yang tak terpisahkan yaitu orientasi mental dan gerakan fisik. Orientasi ialah kemampuan seseorang untuk mengenali lingkungannya dan hubungan dengan menggunakan indera yang masih berfungsi. Sedangkan mobilitas ialah kemampuana seseorang untuk berpindah 
tempat dari suatu tempat ketempat lain yang diinginkan dalam lingkungan sekitar (Sunanto, 2005, hal. 113).

Orientasi dan mobilitas ialah sebuah layanan yang digunakan bagi siswa tunanetra dengan memanfaatkan atau memaksimalkan indera yang masih berguna untuk proses mengenali lingkungan agar dapat bergerak atau berpindah tempat dari suatu tempat ketempat yang lainnya secara mandiri. Orientasi dan mobilitas merupakan salah satu pelajaran yang harus dipelajari oleh siswa tunanetra karena dapat membantu tunanetra dalam berinteraksi sosial dengan lingkungan sekitar maupun akademik saat berada di sekolah (Sunanto, 2005, hal. 114).

Berdasarkan hasil pengamatan di SLB-A TPA Jember, Peneliti menemukan permasalahan bahwa siswa belum mampu mempraktikkan teknikteknik orientasi dan mobilitas pada saat melewati halang rintang yang telah disediakan dalam pembelajaran orientasi dan mobilitas. Agar permasalahan di atas dapat terselesaikan maka peneliti memberikan penanganan supaya siswa tunanetra diberikan tes praktik orientasi dan mobilitas untuk mengetahui teknik yang belum dikuasai serta memperbaiki sikap tubuh pada siswa tunanetra.

Permainan halang rintang adalah kegiatan bermain dengan banyak melewati rintangan yang telah disediakan, permainan halang rintang bermanfaat bagi siswa tunanetra untuk mengasah kemampuan motorik kasarnya, postur tubuh dan cara melangkah dengan benar. Permainan ini merupakan kegiatan yang menarik sesuai dengan karakteristik yang di miliki siswa usia dini, yaitu lebih tertarik mencoba dan suka meniru hal yang dapat menimbulkan rasa ingin tahu yang tinggi (Nurazianti dkk, 2017, hal. 3). Melalui permainan halang rintang ini siswa di harapkan dapat melakukan orientasi dan mobilitas dengan baik. Oleh karena itu perlu adanya kerjasama yang baik antara guru dengan siswa. Media yang digunakan dalam permainan halang rintang ini menggunakan peralatan yang sangat sederhana, yaitu meliputi prasarana yang ada di sekolah seperti bangku, meja, bola plastik dan tali rafia. Pada saat melakukan permainan halang rintang, terdapat beberapa tahapan rintangan dengan pola permainan yang berbeda.

Banyak cara untuk memaksimalkan orientasi dan mobilitas pada siswa tunanetra, diantaranya ialah dengan cara mengajak siswa tunanetra untuk mengikuti sebuah permainan halang rintang. Permainan halang rintang dapat digunakan untuk mengetahui pengaruh kemampuan orientasi dan mobilitas siswa tunanetra, melalui praktik secara langsung dengan instrumen-instrumen yang telah di berikan oleh peneliti. Permainan halang rintang dipilih dalam penelitian ini, 
karena berguna bagi siswa tunanetra sebagai orientasi pada lingkungan baru di kenal maupun lingkungan yang sudah di kenal. Selain itu, siswa tunanetra juga mampu mempraktikkan teknik-teknik yang telah di kuasai sebelumnya.

\section{METODE PENELITIAN}

Penelitian ini menggunakan penelitian eksperimen. Menurut Sugiyono (2016, hal. 72) penelitian eksperimen adalah metode penelitian yang digunakan untuk mencari pengaruh perlakuan tertentu terhadap yang lain dalam kondisi yang terkendalikan. Desain penelitian yang digunakan dalam penelitian ini adalah "One group pre test post test design”, yaitu desain penelitian eksperimen yang dilakukan pretest untuk mengetahui keadaan awal subjek sebelum diberikan perlakukan. Sehingga peneliti dapat mengetahui kondisi subjek yang diteliti sebelum atau sesudah diberikan perlakuan yang hasilnya dapat dibandingkan atau dilihat perubahannya (Saebani, 2017, hal. 256). Pada penelitian ini dapat dilakukan perbandingan antara $\mathrm{O} 1$ (pre test) dan $\mathrm{O} 2$ (post test) agar dapat mengetahui efektifitas perlakuan X (Treatment).

Penelitian ini dilakukan pada bulan Oktober 2018 di SLB-A TPA Jember. Subjek dalam penelitian ini adalah siswa tunanetra kelas IX SMP dengan jumlah 5 siswa tunanetra yang memiliki kemampuan orientasi dan mobilitas yang belum maksimal. Instrumen yang digunakan pada penelitian ini adalah instrumen dengan teknik pengumpulan data dan melalui pemberian tes praktik. Tes praktik berfungsi untuk mengetahui sejauh mana siswa tunanetra memahami orientasi dan mobilitas yang dipraktikkan pada permainan haling rintang.

Adapun prosedur dalam penelitian ini dilakukan dalam tahap persiapan dan tahap pelaksanaan yang di lakukan selama 7 kali pelaksanaan. Menurut Sugiyono (2016, hal. 167) mengemukakan bahwa, penelitian ini menggunakan metode uji tanda Sign test di gunakan untuk menguji hipotesis. Teknis analisis data pada penelitian kuantitatif dilakukan melalui perolehan data uji tanda yang membandingakan antara pre test dan post test. Hal ini bertujuan untuk mempermudah mengolah data apakah ada pengaruh permainan halang rintang terhadap siswa tunanetra di SLB-A TPA Jember.

\section{HASIL DAN PEMBAHASAN}

Berdasarkan hasil pengumpulan data dan analisis dapat dikemukakan beberapa hasil penelitian. Adapun hasil penelitian pre test, intervensi dan post test.

a. Data hasil pre test

Penelitian pre test dimasukkan dengan tujuan untuk mengetahui 
kemampuan orientasi dan

mobilitas

dengan

menggunakan permainan

halang rintang sebelum

diberikan intervensi, pada

saat melakukan pre test

siswa diminta untuk

mempraktikkan orientasi dan

mobilitas dengan cara permainan halang rintang. Adapun hasil pre test permainan halang rintang adalah sebagai berikut:

Tabel 1. Data hasil pre test permainan halang rintang di SLB-A TPA Jember

Tahun

\begin{tabular}{|c|c|c|c|}
\hline $\begin{array}{l}\mathbf{N} \\
\mathbf{0}\end{array}$ & $\begin{array}{c}\text { Nam } \\
\text { a } \\
\text { siswa }\end{array}$ & $\begin{array}{l}\mathbf{L} / \\
\mathbf{P}\end{array}$ & $\begin{array}{c}\text { Nilai } \\
\text { pretes } \\
t\end{array}$ \\
\hline 1 & TK & $\bar{L}$ & 61 \\
\hline 2 & HS & $\mathrm{L}$ & 57 \\
\hline 3 & PT & $\mathrm{P}$ & 57 \\
\hline 4 & RT & $\mathrm{L}$ & 61 \\
\hline 5 & $\mathrm{RF}$ & $\mathrm{L}$ & 61 \\
\hline & \multicolumn{2}{|c|}{ Rata-rata } & 59 \\
\hline
\end{tabular}

Sumber: Arifin (2018)

b. Treatment/ Perlakuan

Pelaksanaan

treatment

membutuhkan 5 kali pertemuan dengan alokasi waktu 35 menit pada setiap pertemuan. Adapun langkahlangkah pelaksanaan treatment/perlakuan adalah sebagai berikut : 1) langkah pertama siswa diajak untuk berjalan lurus dengan menggunakan tongkat maupun tidak menggunakan tongkat dari tahap pertama hingga ketiga. 2) langkah kedua beri arahan bagaimana cara berjalan dan melangkah melewati rintangan dengan benar. 3) langkah ketiga siswa diminta untuk mencari sebuah benda yang ada di sekitarnya. 4) langkah keempat memberikan penjelasan langkah dan gerakan yang benar untuk mencari sebuah benda yang ada di sekitar. Contohnya jika ada benda yang terjatuh, maka langkah pertama yang harus dilakukan siswa ialah mendengarkan arah bunyi suara benda yang jatuh tersebut, kemudian siswa berjalan baik selangkah maupun dua langkah dan dilanjut dengan gerakan jongkok. Selanjutnya gunakan kedua tangan untuk mencari benda jatuh yang ada di sekitar. 5) langkah kelima siswa diajak untuk mendengarkan arah bunyi suara yang di dengar, kemudian siswa berjalan mengikuti arah bunyi suara tersebut hingga memegangnya. 6) langkah keenam memberikan arahan 
agar dapat fokus pada bunyi suara tersebut agar dapat mencarinya tanpa bantuan orang lain. 7) langkah terakhir ialah bertanya kepada siswa tentang permainan halang rintang yang telah dipelajari.

c. Post test

Sedangkan pada tahap akhir dilakukan post test dengan tema yang sama dengan pretest yaitu permainan halang rintang. Berikut hasil posttest orientasi mobilitas pada siswa tunanetra:

Tabel 2. Hasil perolehan skor post test permainan halang rintang

\begin{tabular}{|c|c|c|c|}
\hline No & $\begin{array}{c}\text { Nama } \\
\text { siswa }\end{array}$ & L/P & $\begin{array}{c}\text { Perolehan } \\
\text { Skor }\end{array}$ \\
\hline 1 & TK & L & 17 \\
\hline 2 & HS & L & 16 \\
\hline 3 & PT & P & 15 \\
\hline 4 & RT & L & 17 \\
\hline 5 & RF & L & 16 \\
\hline
\end{tabular}

Sumber: Arifin (2018)

Tabel 3. Hasil nilai akhir post test permainan halang rintang

\begin{tabular}{|c|c|c|c|}
\hline No & $\begin{array}{l}\text { Nama } \\
\text { siswa }\end{array}$ & $\mathbf{L} / \mathbf{P}$ & $\begin{array}{l}\text { Nilai } \\
\text { akhir }\end{array}$ \\
\hline 1 & TK & L & 81 \\
\hline 2 & HS & L & 76 \\
\hline 3 & PT & $\mathrm{P}$ & 71 \\
\hline 4 & RT & $\mathrm{L}$ & 81 \\
\hline 5 & $\mathrm{RF}$ & $\mathrm{L}$ & 76 \\
\hline & \multicolumn{2}{|c|}{ Rata-rata } & 77 \\
\hline
\end{tabular}

Sumber: Arifin (2018)
Tabel probabilitas digunakan untuk melihat kemajuan dan pengaruh yang diberikan antara kegiatan pre test dan post test. Dengan tabel probabilitas tanda sebagai berikut:

Tabel 4. Probabilitas tanda hasil pre test dan hasil post te st terhadap

kemampuan orientasi dan mobi litas pada siswa tunanetra di SLB-A

Jember tahun ajaran 2018/2019

\begin{tabular}{|c|c|c|c|c|}
\hline No & $\begin{array}{l}\text { Nama } \\
\text { siswa }\end{array}$ & $\begin{array}{l}\text { pre } \\
\text { test }\end{array}$ & $\begin{array}{l}\text { post } \\
\text { test }\end{array}$ & $\begin{array}{c}\text { Perubahan } \\
(+/-)\end{array}$ \\
\hline 1 & TK & 61 & 81 & + \\
\hline 2 & HS & 57 & 76 & + \\
\hline 3 & PT & 57 & 71 & + \\
\hline 4 & RT & 61 & 81 & + \\
\hline 5 & $\mathrm{RF}$ & 61 & 76 & + \\
\hline \multicolumn{2}{|c|}{ Rata-rata } & 5 & 77 & $\sum=5$ \\
\hline
\end{tabular}

Berdasarkan hasil analisis data dengan menggunakan rumus uji tanda (sign test) ini menunjukkan bahwa menggunakan permainan halang rintang terhadap kemampuan orientasi dan mobilitas pada siswa tunanetra di SLB-A TPA Jember terbukti pada besarnya nilai $\mathrm{Z}_{\mathrm{H}}$ atau $\mathrm{Z}$ hitung lebih besar dibandingkan dengan nilai $\mathrm{Z}_{\text {tabel }}$ yang saat dilihat pada uji satu sisi sehingga dapat diputuskan Ho ditolak dan Ha diterima, dengan kata lain dapat disimpulkan bahwa ada pengaruh 
yang signifikan penggunaan permainan halang rintang terhadap peningkatan kemampuan orientasi dan mobilitas pada siswa tunanetra di SLB-A TPA Jember tahun ajaran 2018/2019.

Hasil analisis data yang diperoleh diketahui $n=5$, dengan, $\alpha=5 \%(0,05)$, yang kemudian di uji dengan menggunakan rumus uji tanda (sign test) . Selanjutnya hasil yang diperoleh pada pengujian satu sisi di temukan $\mathrm{Z}$ hitung $\left(Z_{\mathrm{H}}\right)=$ 2,236 dan di bandingkan dengan nilai kritis satu sisi 1,645 , sehingga $Z_{\mathrm{H}}>$ $\mathrm{Z}_{\text {tabel }}$ yaitu 2,236 > 1,645, dan dapat dikatakan bahwa Ho ditolak dan $\mathrm{Ha}$ diterima yang artinya ada pengaruh yang signifikan pada penggunaan permainan halang rintang terhadap kemampuan orientasi dan mobilitas pada siswa tunanetra di SLB-A TPA Jember tahun ajaran 2018/2019. Pernyataan di atas dapat dibuktikan dengan adanya selisih nilai yang siswa peroleh pada saat dilakukan post test sebagai akibat dari treatment/perlakuan yang diberikan. Kemampuan orientasi dan mobilitas siswa tunanetra mengalami peningkatan setelah diberikan treatmen/perlakuan dengan menggunakan permainan halang rintang. Hal tersebut dapat diketahui dengan membandingkan hasil belajar yang diperoleh sebelum siswa diberi treatment (pre test) dan setelah siswa diberi treatment/perlakuan (post test) yang menunjukkan adanya selisih yang diperoleh siswa. Adapun hasil dari data yang diperoleh dapat diketahui orientasi dan mobilitas siswa saat pre test rata-rata dibawah standart, namun terjadi peningkatan setelah dilakukan treatment dan post test. Ada beberapa siswa yang tingkat pencapaiannya masih kategori cukup diantaranya ialah siswa PT, RF, dan HS karena kondisi pada saat diberikannya treatment siswa tidak memperhatikan ketika guru memberikan penjelasan tentang permainan halang rintang. Hal tersebut membuktikan bahwa ada pengaruh permainan halang rintang terhadap kemampuan orientasi dan mobilitas pada siswa tunanetra di SLB-A TPA Jember.

\section{PENUTUP}

\section{Simpulan}

Berdasarkan hasil penelitian dan analisis data, maka dapat disimpulkan bahwa permainan halang rintang berpengaruh terhadap kemampuan orientasi dan mobilitas pada siswa tunanetra di SLB-A TPA Jember. Terbukti dari hasil rata-rata pre test yaitu 59 dan hasil post test yaitu 77. Setelah dilakukan treatment/intervensi sebanyak 5 kali. Hasil statistic menggunakan taraf signifikan 5\%. Maka diperoleh $\mathrm{Z}_{\mathrm{H}}=$ 2,236 > 1,645 Ho (Hipotesis nol) ditolak dan Ha (Hipotesis kerja) diterima. Pada pelaksanaan kegiatan penelitian ini terbukti bahwa aspek-aspek permainan halang rintang dapat diterapkan untuk proses belajar orientasi dan mobilitas 
pada siswa tunanetra dalam kehidupan sehari-hari di SLB-A TPA Jember.

\section{Saran}

Berdasarkan hasil penelitian, maka terdapat beberapa pihak yang diharapkan dapat mendukung kegiatan ini adalah sebagai berikut : (1) Kepala Sekolah, menghimbau untuk menjadikan permainan halang rintang sebagai salah satu kegiatan guna meningkatkan kemampuan orientasi dan mobilitas siswa tunanetra. (2) Guru, Memberikan layanan orientasi dan mobilitas pada siswa tunanetra dengan menyesuaikan kemampuan yang dimiliki setiap individu.

\section{DAFTAR PUSTAKA}

Hadi, Purwaka. 2005. Kemandirian Tunanetra. Jakarta: Departemen Pendidikan Nasional Direktorat Jenderal Pendidikan Tinggi Direktorat Pembinaan Pendidikan Tenaga Kependidikan dan Ketenagaan Perguruan Tinggi.
Nurazianti dkk. 2018. Pengaruh Permainan Halang Rintang Terhadap Kemampuan Motorik Kasar Anak Usia 5-6 Tahun di Tk Negeri Pembina 3 Pekanbaru. Surabaya: Universitas Negri Surabaya. (Online). (https://www.neliti.com/id). Diakses 17 Juli 2018.

Saebani, Beni Ahmad. 2017. Pedoman Aplikatif Metode Penelitian dalam Penyusunan Karya Ilmiah, Skripsi, Tesis, dan Disertasi. Bandung: CV Pustaka setia.

Sugiyono, 2016. Metode Penelitian Kuantitatif, Kualitatif, dan $R \& D$. Bandung: CV Alfabeta.

Sunanto, Juang. 2005. Potensi Anak Berkelaian Penglihatan. Jakarta: Departemen Pendidikan Nasional Direktorat Jenderal Pendidikan Tinggi Direktorat Pembinaan Pendidikan Tenaga Kependidikan dan Ketenagaan Perguruan Tinggi. 